\title{
The Role of Citrullination in Inflammatory Bowel Disease: A Neglected Player in Triggering Inflammation and Fibrosis?
}

\author{
Gabriele Dragoni, MD, ${ }^{*,+, \neq, \bullet}$ Gert De Hertogh, $M D, P h D,{ }^{\S}$ and Séverine Vermeire, $M D, P h D^{*, \emptyset}$
}

Citrullination is a posttranslational modification of proteins mediated by a specific family of enzymes called peptidylarginine deiminases (PAD). Dysregulation of these enzymes is involved in the etiology of various diseases, from cancer to autoimmune disorders.

In inflammatory bowel disease (IBD), data for a role of citrullination in the disease process are starting to accumulate at different experimental levels including gene expression analyses, RNA, and protein quantifications. Most data have been generated in ulcerative colitis, but data in Crohn disease are lacking so far.

In addition, the citrullination of histones is the fundamental process promoting inflammation through the formation of neutrophil extracellular traps (NETs). Interestingly, NETs have also been shown to activate fibroblasts into myofibroblasts in fibrotic interstitial lung disease. Therefore, citrullination merits more thorough study in the bowel to determine its role in driving disease complications such as fibrosis.

In this review we describe the process of citrullination and the different players in this pathway, the role of citrullination in autoimmunity with a special focus on IBD, the emerging role for citrullination and NETs in triggering fibrosis, and, finally, how this process could be therapeutically targeted.

Key Words: citrullination, inflammatory bowel disease, neutrophil extracellular traps

\section{INTRODUCTION}

Posttranslational modifications (PTMs) are enzymatic reactions regulating the function and the folding of proteins by converting the substrate in new active groups. These processes result in the formation of new epitopes, potentially acting as neoantigens that are able to alter the immune system

Received for publications March 17, 2020; Editorial Decision April 14, 2020.

From the *KU Leuven Department of Chronic Diseases, Metabolism and Ageing, Translational Research Center for Gastrointestinal Disorders, Leuven, Belgium; Gastroenterology Research Unit, Department of Experimental and Clinical Biomedical Sciences Mario Serio, University of Florence, Florence, Italy;

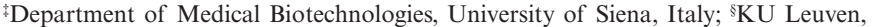
Department of Imaging and Pathology, Translational Cell \& Tissue Research, Leuven, Belgium; 'Department of Gastroenterology and Hepatology, University Hospitals Leuven, KU Leuven, Leuven, Belgium.

Supported by: This work received no sponsored funding.

Conflicts of interest: Gabriele Dragoni received travel grants from AbbVie, Pfizer, and Takeda. For 2020, he is holding a grant on "The role of PADI4 in Crohn's disease: the citrullination of proteins in the transition from inflammation to fibrosis" from the European Crohn's and Colitis Organisation (ECCO). Gert De Hertogh received consulting fees from GlaxoSmithKline, Shire Pharmaceuticals, Teva Pharma, Galapagos, Genentech, Novartis Pharma, Fast Forward Pharmaceuticals, Takeda, and Janssen R\&D. Séverine Vermeire received research support from MSD, AbbVie, Pfizer, Takeda, Janssen; consultancy from AbbVie, MSD, Prometheus Laboratories, Tillotts Pharma, Eli Lilly, Pfizer, Takeda, Janssen, Celgene, Ferring Pharmaceuticals, Arena, Galagapos, Gilead, Hospira, MundiPharma, Progenity, Second Genome, and Biogen; and served on the speakers bureau for AbbVie, Pfizer, Takeda, Janssen, Ferring Pharmaceuticals, Galagapos, GSK, Genentech/Roche, Gilead, Hospira, and Tillotts Pharma.

Address correspondence to: Séverine Vermeire, Department of Gastroenterology and Hepatology, University Hospitals Leuven, KU Leuven, Herestraat 49, 3000 Leuven, Belgium (severine.vermeire@uzleuven.be).

(C) 2020 Crohn's \& Colitis Foundation. Published by Oxford University Press. All rights reserved. For permissions, please e-mail: journals.permissions@oup.com.

doi: 10.1093/ibd/izaa095

Published online 19 May 2020 homeostasis. ${ }^{1}$ Among others, the role of citrullination in activating inflammation and immune response is only partially understood.

Citrullination is a PTM that consists of the deimination, or demethylimination, of positive arginine residues to produce neutral citrulline via specific calcium-binding enzymes called peptidylarginine deiminases (PAD, Fig. 1). ${ }^{2}$ To date, it is believed that citrullination is an irreversible modification of proteins, because no decitrullinating enzymes have been discovered in human tissues. ${ }^{3}$

Five members belong to the PAD family (PAD1, PAD2, PAD3, PAD4, and PAD6), with PAD2 and PAD4 being the most widely expressed and studied. ${ }^{4}$ The unbalanced expression of these enzymes has been shown to be involved in the etiopathogenesis of various diseases, from cancer to many autoimmune and degenerative disorders (Table 1).

\section{INFLAMMATION AND CITRULLINATION}

At first, citrullination was considered a specific trigger for rheumatoid arthritis (RA) because intracellular citrullinated proteins were found in RA synovia but not in samples derived from other synovitides. ${ }^{5}$ The role of citrullination in RA was further confirmed by a significant expression of PAD2 and PAD4 in the monocytes and macrophages of the synovial fluid ${ }^{6}$ and the synovial membrane. ${ }^{7}$, ${ }^{8}$ In addition, this hypothesis was corroborated by in vivo models of induced arthritis where PAD4-knockout mice were showing reduced inflammatory cytokine production (such as anti-tumor necrosis factor- $\alpha$ and interleukin-6 [IL-6]) and less severe joint damage. ${ }^{9,10}$ The impact of citrullination as 


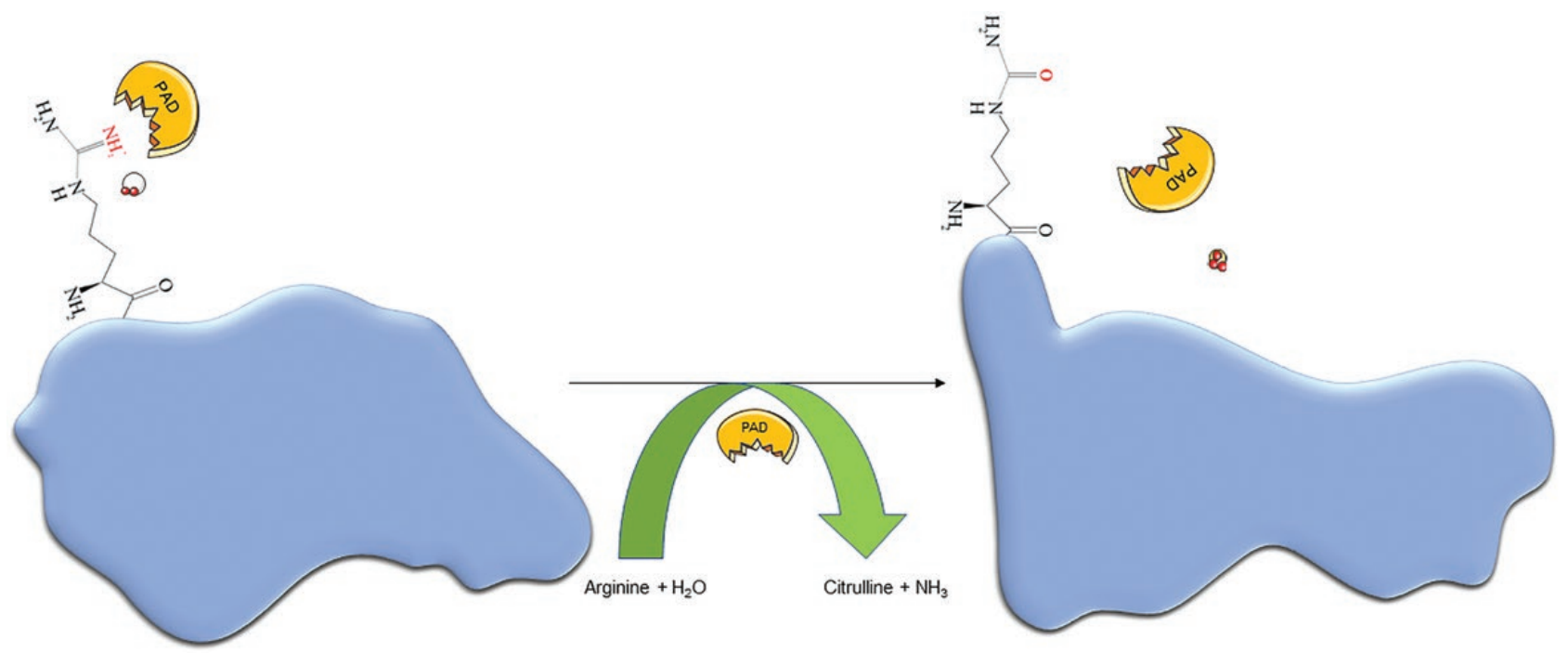

FIGURE 1. Enzymatic reaction of citrullination. Citrullination of positive arginine residues to produce citrulline determines a change in protein folding. This process can result in the modification of protein interactions, with the formation of new epitopes.

TABLE 1. Tissue Expression of the Different PAD enzymes And their Dysregulation in Diseases.

\begin{tabular}{|c|c|c|c|}
\hline & Enzyme Main distribution & Proven Biological Function & Disease Involvement \\
\hline PAD1 & Epidermis; hair follicles; uterus; cancer & $\begin{array}{l}\text { Keratinization of epidermis }{ }^{112} \text {; epithelial-to- } \\
\text { mesenchymal transition }\end{array}$ & $\begin{array}{l}\text { Psoriasis }{ }^{113} \text {; bullous } \\
\text { congenital ichthyosiform } \\
\quad \text { erythroderma }^{114} \text {; breast cancer }{ }^{115}\end{array}$ \\
\hline PAD2 & $\begin{array}{l}\text { Brain; pituitary gland; immune cells; } \\
\text { spleen; skeletal muscle; uterus; hepatic } \\
\text { stellate cells and portal fibroblasts; } \\
\text { kidney; inner ear; pancreas; cancer }\end{array}$ & $\begin{array}{l}\text { Innate immune defense; CNS plasticity and } \\
\text { homeostasis; transcription regulation; } \\
\text { hormone signaling; female reproduction }\end{array}$ & $\begin{array}{l}\text { Rheumatoid arthritis }{ }^{6,7} \text {; mul- } \\
\text { tiple sclerosis }{ }^{17-19} ; \text { Alzheimer } \\
\text { disease }^{20} ; \text { prion disease }^{24} ; \mathrm{UC}^{48} \text {, } \\
\text { 117; RA-ILD and } \mathrm{IPF}^{25} ; \text { breast } \\
\text { cancer }{ }^{118} ; \text { prostate cancer }{ }^{119}\end{array}$ \\
\hline PAD3 & Hair follicles; epidermis & $\begin{array}{l}\text { Control of epidermal keratinization and hair } \\
\text { growth }\end{array}$ & $\begin{array}{l}\text { Loss of barrier function and } \\
\text { epidermal homeostasis }{ }^{120} \\
\text { uncombable hair syndrome }\end{array}$ \\
\hline PAD4 & $\begin{array}{l}\text { Cancer cells; neutrophils; NK cells; mono- } \\
\text { cytes/macrophages; mammary gland } \\
\text { epithelium; brain; bone marrow }\end{array}$ & $\begin{array}{l}\text { NET formation; innate immune response; } \\
\text { transcription regulation via chromatin } \\
\text { decondensation and demethylation }{ }^{122,123} \text {; } \\
\text { tumor aggressive behavior }^{89,90,124}\end{array}$ & $\begin{array}{l}\text { Tumors }{ }^{125-128} ; \text { IBD }^{48} ; \text { RA }^{6} ; \text { multiple } \\
\text { sclerosis }{ }^{129} ; \text { Alzheimer disease } \\
\text { thrombosis and atheroscle- } \\
\text { rosis }^{130} ; \text { RA-ILD and IPF } \\
25,31\end{array}$ \\
\hline PAD6 & Early embryo; ovaries and oocytes; testicles & $\begin{array}{l}\text { Female reproduction and oocytes forma- } \\
\text { tion }^{131,132} \text {; embryo development (mouse) }\end{array}$ & Infertility ${ }^{133,134}$ \\
\hline
\end{tabular}

CNS indicates central nervous system; IPF, idiopathic pulmonary fibrosis; NK, natural killer; RA-ILD, rheumatoid arthritis-associated interstitial lung disease.

a PTM in the pathogenesis of RA is so important that anticitrullinated protein antibodies (ACPAs) are the most specific serological test for the disease today ${ }^{11}$ and are part of the criteria set for diagnosis. ${ }^{12}$ Interestingly, recent evidence has linked (oral) microbial dysbiosis and hypercitrullination in RA: The predominant pathogen of periodontal disease, Porphyromonas gingivalis, expresses a high level of PAD enzymes that lead to the generation of citrullinated peptides as ACPAs and thus the activation of the immune system in individuals genetically predisposed for RA. ${ }^{13}$
Some studies have shown an increased presence of citrullinated peptides in the synovium of other arthritides, ${ }^{14}$, ${ }^{15}$ and immunohistochemical analysis of various tissues has shown a higher level of citrullination in several other inflammatory contexts (polymyositis, chronic tonsillitis, and inflammatory bowel diseases [IBD]). ${ }^{16}$ In our experience with Crohn disease (CD), we did not observe a clear-cut difference of citrullination levels between normal and inflamed tissue from the same patients, but rather variations in the density and nature of the positive staining inflammatory cells (Fig. 2). 


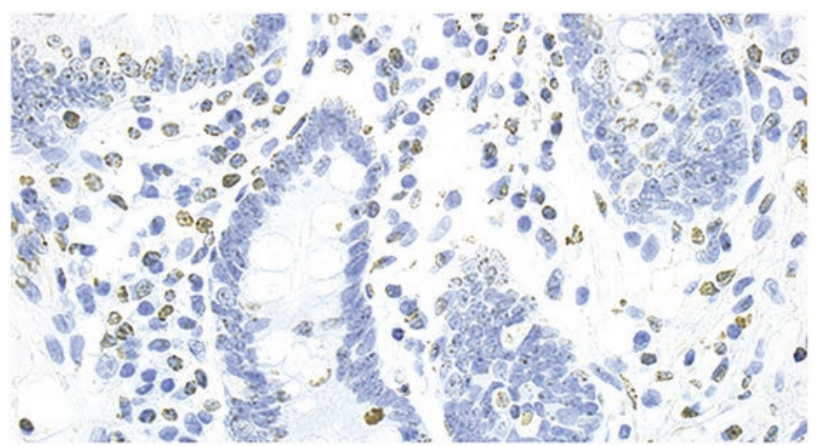

A.

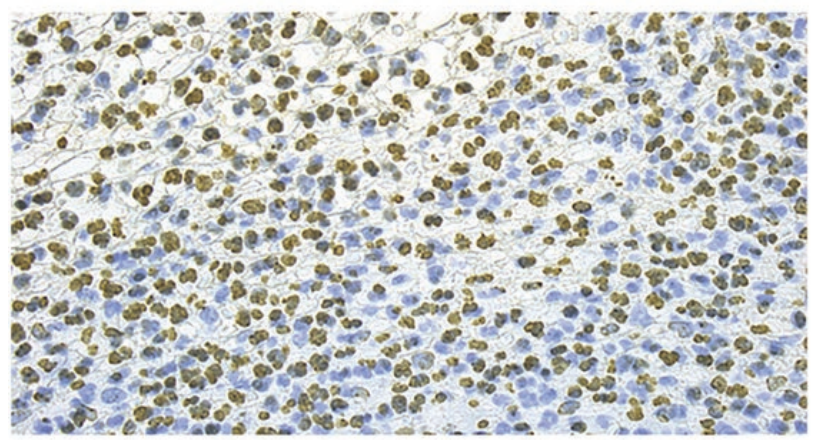

C.

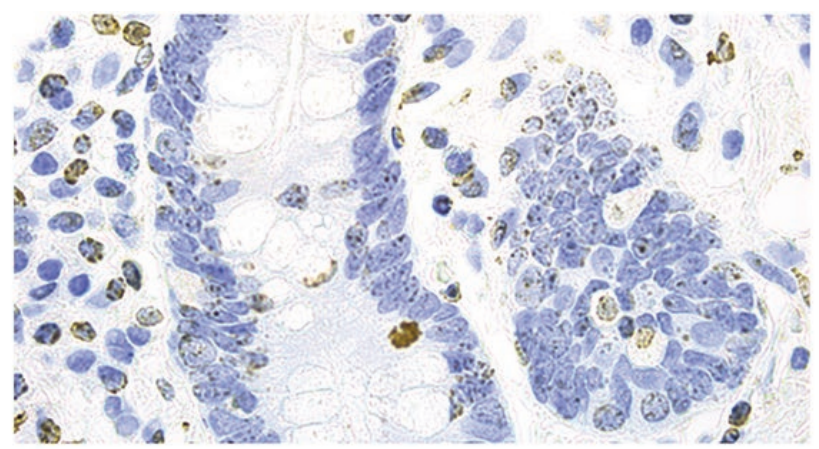

B.

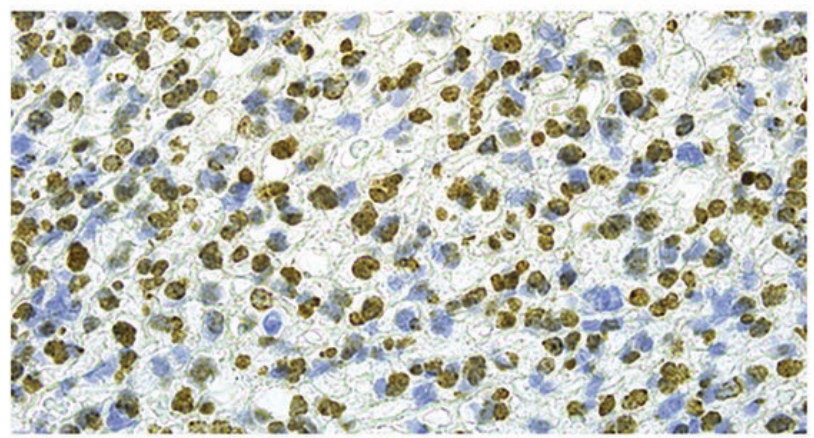

D.

FIGURE 2. Citrulline expression in CD. Comparison of citrullinated peptide expression via immunohistochemistry (F95 anti-peptidyl-citrulline, Merck, Germany) between normal (A, B) and inflamed (C, D) ileum of a patient with CD. A, B, Detail of the deeper mucosa layer of a proximal healthy margin after resection for stricturing $C D$; some intraepithelial and lamina propria lymphocytes show a clear positive nuclear staining (magnification $400 x$ in $A, 630 x$ in B). C, D, Positive staining in the nucleus of many marginated neutrophils overlying an ulcer base (magnification 400x in C, 630x in D). Personal unpublished data.

Excessive citrullination of myelin basic protein by PAD2expressing oligodendrocytes results in the formation of new epitopes along the axon sheaths, leading to autoimmune demyelination typical of multiple sclerosis. ${ }^{17-19}$ Alzheimer disease is another neurodegenerative disorder that has been linked to excessive citrullination and consequent production of autoantibodies, in this case through increased activity of PAD2 and PAD4 in the hippocampal cells. ${ }^{20-22}$ Accordingly, increased citrullinated peptides have also been shown in the substantia nigra neurons of Parkinson disease patients ${ }^{23}$ and in many damaged cerebral areas of patients with prion disease. ${ }^{24}$

Citrullination is also upregulated in lung autoimmune diseases, such as RA-associated interstitial lung disease and idiopathic pulmonary fibrosis, where increased levels of citrullinated peptides and both PAD2 and PAD4 were found in patient granulocytes and macrophages when compared to those of control groups. ${ }^{25,26}$

Taken together, citrullination has to be considered an important step of the inflammatory process across different tissues rather than a disease-specific event. The precise pathogenic mechanism of each inflammatory disorder related to citrullination is currently under investigation, but a common line is probably present in every condition. It is believed that either external insults trigger the upregulation of PAD enzymes in different cell types (mainly innate immune cells) or that bacteria derived from microbial dysbiosis directly overexpress citrullinating enzymes, resulting in the citrullination of various proteins. These new citrullinated peptides could then act as neoantigens, stimulating the formation of antibodies and the activation of adaptive immunity toward the host in genetically predisposed individuals. ${ }^{27,28}$

\section{CITRULLINATION IN FIBROSIS}

In addition to a role in inflammation, data on the potential role of PAD enzymes in fibrosis are starting to accumulate. In RA, citrullination has been associated with a more inflammatory and destructive behavior in synovial fibroblasts, ${ }^{29}$ but recent data on cirrhosis ${ }^{30}$ and idiopathic pulmonary fibrosis ${ }^{31}$ report that citrullination may also activate a profibrogenic response.

The expression of PAD enzymes in liver diseases has been associated with the stage of fibrosis in a series of biopsies from patients with cirrhosis. ${ }^{32}$ In addition, increased serum levels of citrullinated vimentin have been found in a carbon tetrachloride rat model of liver fibrosis..$^{33}$ To selectively study a potential role during fibrosis, Kim et a $^{30}$ studied an experimental mouse 
model of bile duct ligation-induced liver fibrosis and found increased expression of PAD2 together with citrullinated proteins in hepatic stellate cells and $\alpha$-smooth muscle actin-positive portal fibroblasts.

The PAD4-dependent citrullination of histones $\mathrm{H} 1$ and $\mathrm{H} 3$ in the nucleus of neutrophils is the crucial process allowing chromatin decondensation and the subsequent expulsion of neutrophil extracellular traps (NETs). ${ }^{34}$ This process constitutes a unique form of cell death called NETosis. NETs are made of neutrophil granules bound to DNA filaments and are extruded during the first steps of innate immune response in various situations such as cancer, thromboembolic episodes, sepsis, and autoimmunity in general. ${ }^{35,}{ }^{36} \mathrm{In}$ addition, they can directly trigger the immune response toward the self, because some of their granules are potentially modified by citrullination or other PTM reactions ${ }^{37}$ and DNA is able to activate dendritic cells to produce type- 1 interferon. ${ }^{38,39}$

Among other functions, NETs have been shown to mediate the activation of fibroblasts into myofibroblasts in vitro in fibrotic interstitial lung disease. ${ }^{31}$ In particular, after stimulation with NETs, fibroblasts increased their expression of $\alpha$-smooth muscle actin and connective tissue growth factor together with enhanced collagen production and proliferation/migration rates. In the same study, the authors showed a co-localization of myofibroblasts and NETs in lung fibrosis and in skin scar tissue with immunofluorescence, suggesting that this process could be reproduced in different tissue environments. ${ }^{31}$ Moreover, these data have been indirectly corroborated by the findings that age-related myocardial and pulmonary fibrosis are reduced in PAD4-knockout mice because of the reduced amount of NET formation..$^{40}$

Therefore, citrullination-associated enzymes and their products could enhance fibroblast activity via intrinsic and extrinsic pathways, but additional and more robust data are needed in this field.

\section{IBD AND CITRULLINATION}

Improved insights into the pathways driving inflammation in IBD have resulted in the development of monoclonal antibodies or small molecules targeting specific cytokines or their receptors, such as infliximab, ${ }^{41}$ adalimumab ${ }^{42}$ and golimumab ${ }^{43}$ for tumor necrosis factor- $\alpha$; vedolizumab ${ }^{44,45}$ for integrin $\alpha 4 \beta 7$ dependent lymphocyte diapedesis; ustekinumab ${ }^{46}$ for IL-12/ IL-23 Th1 lymphocyte proliferation and differentiation; and tofacitinib ${ }^{47}$ for JAK/STAT nuclear signaling.

However, despite these therapeutic advances, clinical and endoscopic remission rates have reached a ceiling at 30\% to $40 \%$. Explanations may be found in the outcomes used, in the patient populations studied, or in the fact that not all cell types or processes driving inflammation are targeted. In this respect, citrullination may be considered a good candidate because it intervenes in neutrophil and macrophage activation during the initial phases of the innate immune response. The result is the creation of new citrullinated peptides that stimulate the formation of autoantibodies, which are then responsible for the perpetuation of the inflammation (Fig. 3).

The first evidence for the role of citrullination in the context of IBD comes from Makrygiannakis et al ${ }^{16}$ who found a numerically - albeit not significant-higher expression of citrullinated peptides in colonic biopsies of patients with IBD $(\mathrm{n}=10)$ than in control patients $(\mathrm{n}=10)$. Immunohistochemical analysis in both acute dextran sulfate sodium (DSS)-induced colitis and human ulcerative colitis (UC) biopsies has shown a strong staining for PAD2 and PAD4 in inflammatory cells and in the lamina propria cells of affected tissue, confirming the correlation between citrullination and inflammation. ${ }^{48}$ In the same study, a significant reduction in inflammation was seen when mice were treated with $\mathrm{Cl}$-amidine, a potent panPAD inhibitor.

Further evidence comes from genetic studies. In a Japanese cohort of 114 patients with UC, an association between PAD4 haplotype 2 and RA and an inverse association between PAD4 haplotype 1 and UC was reported. ${ }^{49}$ In addition, a selected analysis of PAD enzymes extracted from a genomewide expression profiling of 236 biopsies of newly diagnosed pediatric patients with IBD showed a positive correlation with PAD4 and a negative correlation with PAD2 expression in CD and $\mathrm{UC}$, in both colon and ileum biopsies when compared with those of control patients ${ }^{50}$ (data available at https://www.ebi. ac.uk/gxa/home).

Data about the role of these enzymes in CD, in inflammation and in the context of intestinal fibrosis, are lacking. Interestingly, no study has yet investigated in IBD the potential role of the gut microbiome in enhancing the citrullination cascade, as reported in RA, independently from eventual external insults.

\section{NETS IN IBD}

In consideration of the recent discovery of NETs, ${ }^{51}$ only few studies have been published in IBD on this topic, with some authors claiming their presence in both $\mathrm{UC}$ and $\mathrm{CD}^{52-54}$ and some others confirming this evidence only in UC. ${ }^{55,56}$

The first publication analyzed colonic biopsies from 10 patients with macroscopically inactive UC and 10 control patients at the proteomic and histological level, with the conclusion that NET-related proteins were more abundant in the UC group (on average 42.2 folds; $P<0.0005$ ). ${ }^{57}$ An additional pathological evaluation of active $\mathrm{CD}$ and $\mathrm{UC}$, with biopsies taken from the terminal ileum and colon, respectively, showed an abundant presence of NETs in both diseases in comparison to no NET detection in the healthy control group. ${ }^{52}$ These findings were recently confirmed in actively inflamed colonic biopsies of patients with $\mathrm{UC}$ and $\mathrm{CD}$ when compared with sites of inactive IBD and control patients. ${ }^{54}$ Moreover, to show a link between 


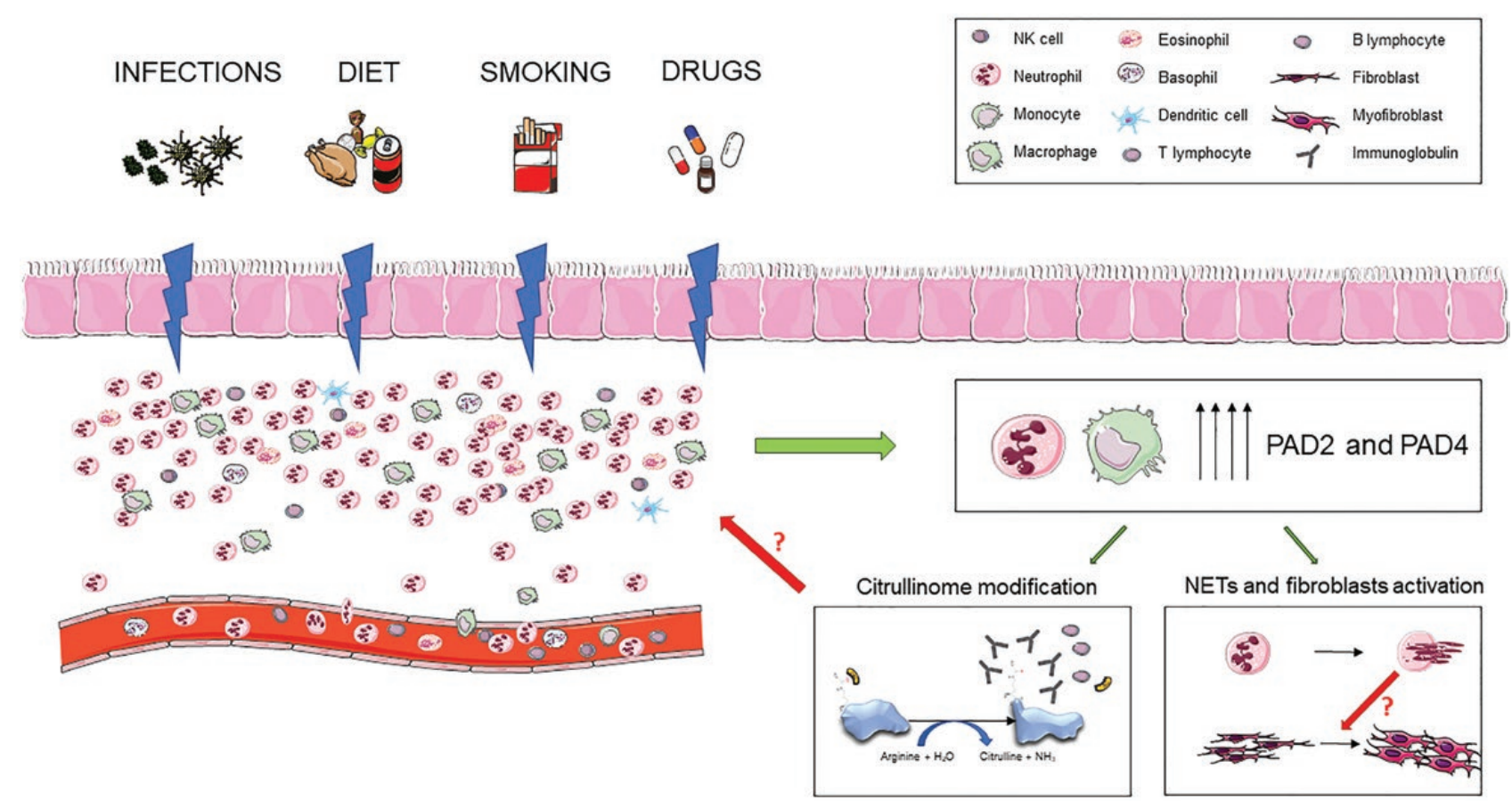

FIGURE 3. Proposed pathogenesis of citrullination in IBD. External insults to the intestinal mucosa trigger innate immune activation in genetically predisposed individuals. Neutrophils and monocytes/macrophages increase their expression of PAD2 and PAD4 enzymes, resulting in modification of the physiological citrullinome and the formation of new autoantibodies. In addition, PAD4 is responsible for NET formation in the inflammatory infiltration.

NETs and the activation of a hypercoagulable state, He and colleagues $^{53}$ described the presence of these extracellular filaments in the peripheral blood of patients with active UC and active $\mathrm{CD}$, but not in patients with inactive disease.

Another analysis of colonic biopsies and peripheral blood neutrophils of 23 patients with UC and 11 patients with CD showed an abundance of NETs in UC but not in CD..$^{55}$ Dinallo et al ${ }^{56}$ confirmed the UC specificity by Western blot analysis and immunohistochemistry.

The reasons for these conflicting results in IBD inflammation should probably be found in the relatively small cohorts investigated and the heterogeneous sampling of ileal and colonic biopsies. More data on larger numbers are needed to clarify whether the presence of NETs is exclusive to UC or at least more relevant in its pathogenesis compared with $\mathrm{CD}$.

Interestingly, in the lung NETs can trigger the fibrogenic process when put in co-culture with fibroblasts; they enhance the activation of fibroblasts into myofibroblasts and the production of collagens. ${ }^{31}$ A similar mechanism is thought to be involved in age-related cardiac fibrosis as shown in a PAD4knockout model of mouse fibrosis. ${ }^{40}$ Therefore, citrullination and NETs also merit study in IBD to determine their role in driving disease complications (Fig. 3).

From a therapeutic point of view, a profibrogenic role of NETs in the human intestine could open avenues for the development of powerful drugs with the ability to control both inflammation and fibroblast activation. This dual action is what could break the above-mentioned therapeutic efficacy ceiling, because intestinal fibrosis is autopropagative when triggered by inflammation and hence should also be targeted separately. ${ }^{58}$

Specifically, combined regimens tackling the innate and adaptive inflammatory responses together with a treatment to contrast fibroblast activation are presumably the primary strategies that will be tested and adopted in the future of IBD management, until preventive measures are available.

\section{THE CITRULLINOME}

There is now robust evidence for increased citrullination and hyperexpression of PAD enzymes in many autoimmune disorders. The total amount of citrullinated proteins constitutes the so-called citrullinome. The challenge for research in this field is to identify the specific proteins that are citrullinated in the different immune-mediated diseases.

To date, only few substrates of PADs have been found because of technical issues related to the exiguous mass change of a protein after citrullination (only $+0.98 \mathrm{Da}$ ) ${ }^{59}$ Two probes (rhodamine-phenylglyoxal and biotin-phenylglyoxal) ${ }^{60,61}$ have thus recently been developed with the ability to chemoselectively bind and isolate citrullinated substrates. These probes can then be subsequently highlighted with specific fluorescent staining. This novel technique enables researchers to "split" the citrullinome into different groups of proteins based on their 
weight. As an example, Bicker et $\mathrm{a}^{60}$ reported in their previous model of colitis that $\mathrm{Cl}$-amidine reduced citrullination in proteins placed at $25,50,70$, and $100 \mathrm{kDa}$ but not in those at 10 $\mathrm{kDa}{ }^{60}$ Yet the limitation of this novel method is still the inability to identify the specific proteins within a given cluster. Proteomic analysis is therefore needed to provide more insights about citrullination biology. ${ }^{61}$

Initial experiments in RA tried to identify citrullinated proteins in the synovium, synovial fluid, and serum of patients. In their comparison between 16 patients with RA and 16 healthy control patients, Tilvawala et al ${ }^{59}$ discovered approximately 150 new substrates of citrullination such as serpins, serine proteases, and glycolytic enzymes. Additional proteomics analysis on the synovial fluid of patients with RA using a mass-spectrometry approach identified 9 new sites of the citrullination of fibrinogen chains, which may help in acquiring more information on the disease's evolution. ${ }^{62}$

In general, the step of protein identification is fundamental for further selective downstream analyses toward the understanding of citrullination mechanisms. In fact, proteomic studies may not tell whether a protein is physiologically citrullinated or whether it is involved in disease pathogenesis.

A thorough examination of the citrullinome pool in IBD is crucial to provide more insights on the effect of citrullination in normal, inflamed, and fibrotic bowel and to offer information about the class of inhibitors to be preferred in these contexts.

\section{BIOMARKERS OF CITRULLINATION}

In the field of citrullination, the first and only markers that are currently used in clinical practice are ACPAs, which are significantly more sensitive and specific than the rheumatoid factor for the diagnosis of RA. ${ }^{63}$ In addition, ACPAs are predictive of RA onset because increased levels are found very early in the preclinical context of the disease. ${ }^{64}$ For other autoimmune diseases in which citrullination plays a role, there is no evidence that ACPAs can be used for these purposes, including IBD. ${ }^{65-68}$ Therefore, the study of the citrullinome could also help identify new specific antibodies to be used for diagnostic and prognostic purposes in IBD (Fig. 4).

In the last few years, many groups have started to address the potential value of NET serum markers, in both inflammation and thromboembolism. Despite the lack of standardized methods to assess their formation, ${ }^{69}$ a few components have been tested in different scenarios.

The citrullinated histone $\mathrm{H} 3$ (H3cit) is produced during the PAD4-dependent histone citrullination as a fundamental step in chromatin decondensation and the NETosis process. Increased blood levels of H3cit have been found in 2 rodent models of lipopolysaccharide-induced septic shock in the first hours after disease onset ${ }^{70,71}$; these results have been confirmed in a human model of endotoxemia, suggesting that $\mathrm{H} 3$ cit could predict the lethality of sepsis in the early phases of disease. ${ }^{72}$ Serum H3cit levels have been linked to an enhanced inflammatory state related to advanced cancer and have been associated with poor prognosis. ${ }^{73,74}$

Another component of NETs, the myeloperoxidase (MPO)-DNA complex, has been studied in inflammatory conditions. High serum levels of MPO-DNA have been associated with worse outcomes (clinical instability, prolonged stay in the hospital, and overall mortality at 30 days) in patients with
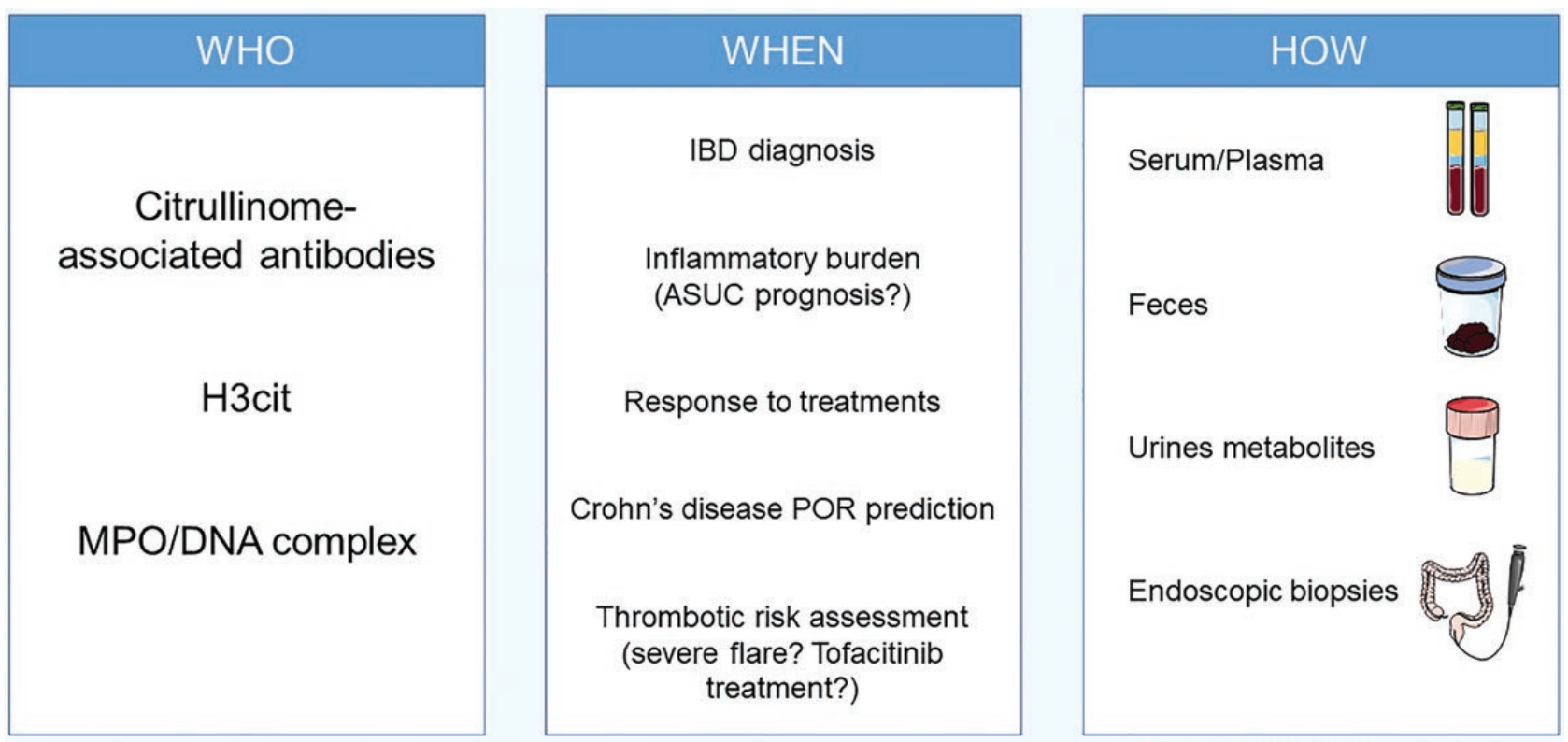

FIGURE 4. Citrullination biomarkers and IBD. Potential clinical applications where biomarkers of citrullination in IBD could play a role. ASUC indicates acute severe ulcerative colitis; POR, postoperative recurrence. 
community-acquired pneumonia. ${ }^{75}$ Accordingly, the MPODNA complex is increased in the bronchoalveolar lavage fluid of patients with ventilator-associated pneumonia when compared with that of critically ill patients without inflammatory burden and infection in the lung. ${ }^{76}$

Neutrophil granules released with chromosomal DNA during NET formation are able to trigger thrombosis by trapping platelets and various procoagulant factors. ${ }^{77,78}$ As a consequence, NETs have been found in clots, in both coronary and venous systems. ${ }^{79-81}$ For all these reasons, it is not surprising that $\mathrm{H} 3$ cit levels are increased in patients with acute ischemic stroke, especially in those with more severe course and higher risk of mortality at 1 year. ${ }^{82}$ In addition, serum H3cit levels correlate with the risk of venous thromboembolism in patients with advanced cancer, ${ }^{83}$ although data are conflicting. ${ }^{74}$

In addition, the MPO-DNA complex has been studied and found to be increased in the context of antiphospholipid syndrome. ${ }^{84}$ However, the MPO-DNA complex was not associated with clinical outcomes or hypercoagulability in a cohort of 1001 patients with stable coronary artery disease, ${ }^{85}$ despite its positive correlation with severe calcifications and atherosclerotic evolution of coronaries. ${ }^{86}$

In IBD, only 1 work has addressed this topic, showing that MPO-DNA complexes are predominantly expressed in patients with active UC and CD when compared with patients with inactive IBD and control patients. ${ }^{54}$ The same authors reported an attenuation of platelet activation and thrombus formation with the use of DNase in a murine DSS-induced model of acute colitis, showing a link between NETs and the prothrombotic state of active IBD. ${ }^{54}$

In consideration of the prognostic value of $\mathrm{H} 3 \mathrm{cit}$ and MPO-DNA in some acute inflammatory events, it could be interesting to evaluate these proteins in patients with acute severe UC to see whether they can predict colectomy.

In addition, in light of the recent warnings about deep vein thrombosis and pulmonary embolism with higher doses of the JAK inhibitor tofacitinib, ${ }^{87,88}$ the aforementioned markers merit investigation to see if a prognostic role can be identified.

\section{TARGETING CITRULLINATION: PAD-INHIBITORS}

The PAD enzymes (especially PAD4) are aberrantly expressed in some tumors with more aggressive behavior and are involved in cancer-related neoangiogenesis and stromal activation ${ }^{89}, 90$; thus, many efforts are currently being undertaken to find specific inhibitors to be used as antineoplastic agents. The strategy in chronic inflammatory disorders is to test the same components as anti-inflammatory and antifibrotic drugs. Several potential drugs with irreversible (covalent) and reversible (noncovalent) PAD inhibition have been tested (Table 2).

Initially, the role of the first-generation PAD-inhibitors F-amidine and $\mathrm{Cl}$-amidine was investigated: Both compounds have been shown to reduce the vitality in vitro of leukemic cells and epithelial cancer cells derived from colon and mammalian cancer at micromolar concentration, with no toxic effect on normal cells. ${ }^{91}$ Promising results have also been reported for the anti-inflammatory effect of $\mathrm{Cl}$-amidine in mouse models of disease including acute DSS-related colitis, ${ }^{48}$ collagen-induced arthritis, ${ }^{92}$ murine lupus, ${ }^{93,94}$ and atherosclerosis. ${ }^{95}$

Despite the wide utilization of $\mathrm{Cl}$-amidine in animal models, many limitations have impeded its clinical evaluation: low selectivity for a specific PAD enzyme, short half-life in vivo, low potency, limited bioavailability, and irreversible binding. For all these reasons, second-generation irreversible inhibitors with structure modification were developed: o-F-amidine and o-Cl-amidine. ${ }^{96}$ In detail, o-F-amidine is 65 times more potent than the corresponding F-amidine and is at least 6 times more selective for PAD1; o-Cl-amidine is also more selective than first-generation $\mathrm{Cl}$-amidine, more specifically blocking PAD1 and PAD4. ${ }^{96}$ Another interesting component of this "family" is BB-Cl-amidine with a benzimidazol tail, which has resulted in higher selectivity toward PAD2 in a model of collagen-induced arthritis. $^{97}$

The unmet need of highly selective inhibitors together with the improvement of bioengineering and pharmaceutical technologies eventually resulted in the third-generation compounds Thr-Asp-F-amidine and Thr-Asp-Cl-amidine, with high selectivity and high efficacy in irreversibly blocking PAD4. ${ }^{98}$ Streptonigrin also has high specificity for PAD4, around 37 times higher than $\mathrm{Cl}$-amidine, and is considered today as one of the most powerful selective inhibitors. ${ }^{99} \mathrm{It}$ is not a surprise that this molecule has also started to be tested in in vivo experiments of IBD, as in the acute DSS model of colitis. ${ }^{56}$

In the end, the research on selective but reversible inhibitors is still ongoing. In fact, the early discovery of a few antibiotics (streptomycin, minocycline, chlorotetracycline) ${ }^{100}$ and antineoplastic agents (taxol) ${ }^{101}$ with a relatively low inhibitory action for PAD4 has not been followed by improvements in subsequent years. Recently, some new reversible inhibitors of PAD1, ${ }^{102}$ PAD2, ${ }^{103}$ and PAD4 ${ }^{104-110}$ have been tested in biochemical assays and in cell-based models and in vivo with promising results, but they need further validation before consideration for clinical human studies.

\section{OPEN QUESTIONS AND FUTURE SCENARIOS}

In conclusion, citrullination is involved in many different steps of human physiology, but also in pathology. A better understanding of its mechanisms in IBD could provide a new target for anti-inflammatory treatments. In order to achieve this goal, many questions remain to be solved. First, there are no data on PAD enzyme expression levels in $\mathrm{CD}$, and only $\mathrm{UC}$ has been studied so far. In addition, it is unknown which proteins specifically are citrullinated during the inflammatory process in IBD, and a detailed analysis of the citrullinome is mandatory to increase knowledge on this topic. Moreover, some products of neutrophil citrullination (ie, NET compounds) have shown the potential of reliable inflammatory markers. Therefore, the 
TABLE 2. PAD Inhibitors Tested in Experimental Contexts.

\begin{tabular}{|c|c|c|c|}
\hline Agent & Binding Reversibility & Relative Selectivity* & Setting of Experimental Testing \\
\hline Cl-amidine & Irreversible & Pan-inhibitor & $\begin{array}{l}\text { In vitro }{ }^{91,107,123,135-137} \text { and in vivo }{ }^{48,-95,138,139}\end{array}$ \\
\hline F-amidine & Irreversible & Pan-inhibitor & In vitro 91,140 \\
\hline o-Cl-amidine & Irreversible & PAD1 and PAD4 & Biochemical assays and in vitro ${ }^{96}$ \\
\hline o-F-amidine & Irreversible & PAD1 & Biochemical assays and in vitro ${ }^{96}$ \\
\hline BB-Cl-amidine & Irreversible & PAD2 & In vitro ${ }^{107}$ and in vivo ${ }^{97}$ \\
\hline Cl4-amidine and F4-amidine & Irreversible & PAD3 & Biochemical assays ${ }^{141}$ \\
\hline Thr-Asp-F-amidine & Irreversible & PAD4 & In vitro ${ }^{98}$ \\
\hline Thr-Asp-Cl-amidine & Irreversible & PAD1 and PAD4 & In vitro 98 \\
\hline $\mathrm{d}$-Cl-amidine and d-o-F-amidine & Irreversible & PAD1 & Biochemical assays and in vitro ${ }^{142}$ \\
\hline 2-chloroacetamidine & Irreversible & PAD2 & In vitro and in vivo ${ }^{143}$ \\
\hline Biphenyl tetrazole tert-butyl Cl-amidine & Irreversible & PAD4 & Biochemical assays and in vitro ${ }^{144}$ \\
\hline Streptonigrin & Irreversible & PAD4 & Biochemical assays ${ }^{99}$ and in vivo ${ }^{56}$ \\
\hline Fluoroacetamidine-containing inhibitor & Reversible & PAD1 & Biochemical assays and in vitro ${ }^{102}$ \\
\hline GSK199 and GSK484 & Reversible & PAD4 & $\begin{array}{l}\text { Biochemical assays, in vitro, }{ }^{106,107} \\
\text { and in vivo }{ }^{108,109}\end{array}$ \\
\hline $\begin{array}{l}\text { 5,5-Dimethyl-3-(1-piperazinylmethyl)- } \\
\text { 2,4-imidazolidinedione }\end{array}$ & Reversible & PAD4 & In vivo $^{110}$ \\
\hline LT02193089 & Reversible & PAD4 & Biochemical assays and in vitro ${ }^{105}$ \\
\hline YW3-56 & NA & PAD4 & Biochemical assays and in vitro ${ }^{145}$ \\
\hline $\mathrm{N}$-imidazole hydantoin compound & Reversible & PAD2 & Biochemical assays and in vivo ${ }^{103}$ \\
\hline Benzamide analogue compound & NA & PAD3 & Biochemical assays and in vitro ${ }^{146}$ \\
\hline
\end{tabular}

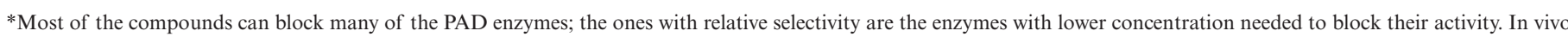
refers to animal models.

NA indicates not available.

accuracy of these markers in the context of active inflammation should be studied and compared to established markers, such as CRP and fecal calprotectin. ${ }^{111}$ Whether accuracy should be checked in serum, feces, or urine is not yet known and requires studies.

Finally, the stimulating effect of NETs in pulmonary fibroblast cell lines should be also investigated in the context of the intestine, because a confirmation of these findings could result in new targets for antifibrotic therapy research.

\section{ACKNOWLEDGMENTS}

All figures were made with SMART (Servier Medical ART, by Servier), which are licensed under a Creative Commons Attribution 3.0 Unported License (https://smart.servier. $\mathrm{com} /)$.

\section{REFERENCES}

1. Liu J, Qian C, Cao X. Post-translational modification control of innate immunity. Immunity. 2016;45:15-30.

2. van Venrooij WJ, van Beers JJ, Pruijn GJ. Anti-CCP antibodies: the past, the present and the future. Nat Rev Rheumatol. 2011;7:391-398.

3. Gudmann NS, Hansen NU, Jensen AC, et al. Biological relevance of citrullinations: diagnostic, prognostic and therapeutic options. Autoimmunity. 2015;48:73-79.

4. Wang S, Wang Y. Peptidylarginine deiminases in citrullination, gene regulation, health and pathogenesis. Biochim Biophys Acta. 2013;1829:1126-1135.
5. Baeten D, Peene I, Union A, et al. Specific presence of intracellular citrullinated proteins in rheumatoid arthritis synovium: relevance to antifilaggrin autoantibodies. Arthritis Rheum. 2001;44:2255-2262.

6. Vossenaar ER, Radstake TR, van der Heijden A, et al. Expression and activity of citrullinating peptidylarginine deiminase enzymes in monocytes and macrophages. Ann Rheum Dis. 2004;63:373-381.

7. De Rycke L, Nicholas AP, Cantaert T, et al. Synovial intracellular citrullinated proteins colocalizing with peptidyl arginine deiminase as pathophysiologically relevant antigenic determinants of rheumatoid arthritis-specific humoral autoimmunity. Arthritis Rheum. 2005;52:2323-2330.

8. Foulquier C, Sebbag M, Clavel C, et al. Peptidyl arginine deiminase type 2 (PAD2) and PAD-4 but not PAD-1, PAD-3, and PAD-6 are expressed in rheumatoid arthritis synovium in close association with tissue inflammation. Arthritis Rheum. 2007;56:3541-3553.

9. Suzuki A, Kochi Y, Shoda H, et al. Decreased severity of experimental autoimmune arthritis in peptidylarginine deiminase type 4 knockout mice. $B M C$ Musculoskelet Disord. 2016;17:205.

10. Seri Y, Shoda H, Suzuki A, et al. Peptidylarginine deiminase type 4 deficiency reduced arthritis severity in a glucose-6-phosphate isomerase-induced arthritis model. Sci Rep. 2015;5:13041.

11. Taylor P, Gartemann J, Hsieh J, Creeden J. A systematic review of serum biomarkers anti-cyclic citrullinated peptide and rheumatoid factor as tests for rheumatoid arthritis. Autoimmune Dis. 2011;2011:815038.

12. Aletaha D, Neogi T, Silman AJ, et al. 2010 Rheumatoid arthritis classification criteria: an American College of Rheumatology/European League Against Rheumatism collaborative initiative. Arthritis Rheum. 2010;62:2569-2581.

13. de Molon RS, Rossa C, Thurlings RM, et al. Linkage of periodontitis and rheumatoid arthritis: current evidence and potential biological interactions. Int $\mathrm{J} \mathrm{Mol}$ Sci. 2019;20:E4541.

14. Vossenaar ER, Smeets TJ, Kraan MC, et al. The presence of citrullinated proteins is not specific for rheumatoid synovial tissue. Arthritis Rheum. 2004:50:3485-3494

15. Sipilä KH, Ranga V, Rappu P, et al. Joint inflammation related citrullination of functional arginines in extracellular proteins. Sci Rep. 2017;7:8246.

16. Makrygiannakis D, af Klint E, Lundberg IE, et al. Citrullination is an inflammation-dependent process. Ann Rheum Dis. 2006;65:1219-1222. 
17. Moscarello MA, Pritzker L, Mastronardi FG, et al. Peptidylarginine deiminase: a candidate factor in demyelinating disease. J Neurochem. 2002;81:335-343.

18. Raijmakers R, Vogelzangs J, Croxford JL, et al. Citrullination of central nervous system proteins during the development of experimental autoimmune encephalomyelitis. J Comp Neurol. 2005;486:243-253.

19. Yang L, Tan D, Piao H. Myelin basic protein citrullination in multiple sclerosis: a potential therapeutic target for the pathology. Neurochem Res. 2016;41:1845-1856.

20. Ishigami A, Ohsawa $T$, Hiratsuka $M$, et al. Abnormal accumulation of citrullinated proteins catalyzed by peptidylarginine deiminase in hippocampal extracts from patients with Alzheimer's disease. J Neurosci Res. 2005;80:120-128.

21. Ishigami A, Masutomi $\mathrm{H}$, Handa $\mathrm{S}$, et al. Mass spectrometric identification of citrullination sites and immunohistochemical detection of citrullinated glial fibrillary acidic protein in Alzheimer's disease brains. J Neurosci Res. 2015:93:1664-1674.

22. Acharya NK, Nagele EP, Han M, et al. Neuronal PAD4 expression and protein citrullination: possible role in production of autoantibodies associated with neurodegenerative disease. J Autoimmun. 2012;38:369-380

23. Nicholas AP. Dual immunofluorescence study of citrullinated proteins in Parkinson diseased substantia nigra. Neurosci Lett. 2011;495:26-29.

24. Jang B, Ishigami A, Maruyama N, et al. Peptidylarginine deiminase and protein citrullination in prion diseases: strong evidence of neurodegeneration. Prion 2013;7:42-46.

25. Samara KD, Trachalaki A, Tsitoura E, et al. Upregulation of citrullination pathway: from autoimmune to idiopathic lung fibrosis. Respir Res. 2017;18:218

26. Bongartz T, Cantaert T, Atkins SR, et al. Citrullination in extra-articular manifestations of rheumatoid arthritis. Rheumatology (Oxford). 2007;46:70-75.

27. Darrah E, Andrade F. Rheumatoid arthritis and citrullination. Curr Opin Rheumatol. 2018;30:72-78.

28. Valesini G, Gerardi MC, Iannuccelli C, et al. Citrullination and autoimmunity. Autoimmun Rev. 2015;14:490-497.

29. Sanchez-Pernaute O, Filkova M, Gabucio A, et al. Citrullination enhances the pro-inflammatory response to fibrin in rheumatoid arthritis synovial fibroblasts. Ann Rheum Dis. 2013;72:1400-1406.

30. Kim SE, Park JW, Kim MJ, et al. Accumulation of citrullinated glial fibrillary acidic protein in a mouse model of bile duct ligation-induced hepatic fibrosis. PLoS One. 2018;13:e0201744.

31. Chrysanthopoulou A, Mitroulis I, Apostolidou E, et al. Neutrophil extracellular traps promote differentiation and function of fibroblasts. $J$ Pathol. 2014;233:294-307.

32. Abdeen SM, Olusi SO. Peptidyl arginine deiminase: A novel immunohistochemical marker for liver fibrosis in patients with chronic hepatitis. Acta Histochem. 2010;112:592-603.

33. Vassiliadis E, Oliveira CP, Alvares-da-Silva MR, et al. Circulating levels of citrullinated and MMP-degraded vimentin (VICM) in liver fibrosis related pathology. Am J Transl Res. 2012;4:403-414.

34. Papayannopoulos V. Neutrophil extracellular traps in immunity and disease. Nat Rev Immunol. 2018;18:134-147.

35. Skopelja-Gardner S, Jones JD, Rigby WFC. "NETtling" the host: Breaking of tolerance in chronic inflammation and chronic infection. $J$ Autoimmun. 2018;88:1-10.

36. Sørensen OE, Borregaard N. Neutrophil extracellular traps - the dark side of neutrophils. $J$ Clin Invest. 2016:126:1612-1620.

37. Bruschi M, Petretto A, Bertelli R, et al. Post-translational modified proteins are biomarkers of autoimmune-processes: NETosis and the inflammatoryautoimmunity connection. Clin Chim Acta. 2017;464:12-16.

38. Garcia-Romo GS, Caielli S, Vega B, et al. Netting neutrophils are major inducers of type I IFN production in pediatric systemic lupus erythematosus. Sci Transl Med. 2011;3:73ra20.

39. Lande R, Ganguly D, Facchinetti V, et al. Neutrophils activate plasmacytoid dendritic cells by releasing self-DNA-peptide complexes in systemic lupus erythematosus. Sci Transl Med. 2011;3:73ra19.

40. Martinod K, Witsch T, Erpenbeck L, et al. Peptidylarginine deiminase 4 promotes age-related organ fibrosis. J Exp Med. 2017;214:439-458.

41. Rutgeerts P, Sandborn WJ, Feagan BG, et al. Infliximab for induction and maintenance therapy for ulcerative colitis. $N$ Engl J Med. 2005;353:2462-2476.

42. Hanauer SB, Sandborn WJ, Rutgeerts P, et al. Human anti-tumor necrosis factor monoclonal antibody (adalimumab) in Crohn's disease: the CLASSIC-I trial. Gastroenterology. 2006;130:323-333.

43. Sandborn WJ, Feagan BG, Marano C, et al.; PURSUIT-Maintenance Study Group. Subcutaneous golimumab maintains clinical response in patients with moderate-to-severe ulcerative colitis. Gastroenterology. 2014;146:96-109.e1.

44. Feagan BG, Rutgeerts P, Sands BE, et al.; GEMINI 1 Study Group. Vedolizumab as induction and maintenance therapy for ulcerative colitis. $N$ Engl J Med. 2013;369:699-710.

45. Sandborn WJ, Feagan BG, Rutgeerts P, et al.; GEMINI 2 Study Group. Vedolizumab as induction and maintenance therapy for Crohn's disease. $N$ Engl J Med. 2013;369:711-721.
46. Feagan BG, Sandborn WJ, Gasink C, et al.; UNITI-IM-UNITI Study Group. Ustekinumab as induction and maintenance therapy for Crohn's disease. $N E n g$ J Med. 2016:375:1946-1960.

47. Sandborn WJ, Su C, Sands BE, et al.; OCTAVE Induction 1, OCTAVE Induction 2, and OCTAVE Sustain Investigators. Tofacitinib as induction and maintenance therapy for ulcerative colitis. N Engl J Med. 2017;376:1723-1736.

48. Chumanevich AA, Causey CP, Knuckley BA, et al. Suppression of colitis in mice by $\mathrm{Cl}$-amidine: a novel peptidylarginine deiminase inhibitor. Am J Physio Gastrointest Liver Physiol. 2011;300:G929-G938.

49. Chen CC, Isomoto H, Narumi Y, et al. Haplotypes of PADI4 susceptible to rheumatoid arthritis are also associated with ulcerative colitis in the Japanese population. Clin Immunol. 2008;126:165-171.

50. Howell KJ, Kraiczy J, Nayak KM, et al. DNA methylation and transcription patterns in intestinal epithelial cells from pediatric patients with inflammatory bowel diseases differentiate disease subtypes and associate with outcome. Gastroenterology. 2018;154:585-598.

51. Brinkmann V, Reichard U, Goosmann C, et al. Neutrophil extracellular traps kill bacteria. Science. 2004;303:1532-1535

52. Gottlieb Y, Elhasid R, Berger-Achituv S, et al. Neutrophil extracellular traps in pediatric inflammatory bowel disease. Pathol Int. 2018;68:517-523.

53. He Z, Si Y, Jiang T, et al. Phosphotidylserine exposure and neutrophil extracellular traps enhance procoagulant activity in patients with inflammatory bowe disease. Thromb Haemost. 2016;115:738-751.

54. Li T, Wang C, Liu Y, et al. Neutrophil extracellular traps induce intestinal damage and thrombotic tendency in inflammatory bowel disease. J Crohns Colitis. 2020;14:240-253.

55. Angelidou I, Chrysanthopoulou A, Mitsios A, et al. REDD1/autophagy pathway is associated with neutrophil-driven IL-1 $\beta$ inflammatory response in active ulcerative colitis. J Immunol. 2018;200:3950-3961.

56. Dinallo V, Marafini I, Di Fusco D, et al. Neutrophil extracellular traps sustain inflammatory signals in ulcerative colitis. J Crohns Colitis. 2019;13:772-784.

57. Bennike TB, Carlsen TG, Ellingsen T, et al. Neutrophil extracellular traps in ulcerative colitis: a proteome analysis of intestinal biopsies. Inflamm Bowel Dis. 2015;21:2052-2067.

58. Johnson LA, Luke A, Sauder K, et al. Intestinal fibrosis is reduced by early elimination of inflammation in a mouse model of IBD: impact of a "top-down" approach to intestinal fibrosis in mice. Inflamm Bowel Dis. 2012;18:460-471.

59. Tilvawala R, Nguyen SH, Maurais AJ, et al. The rheumatoid arthritis-associated citrullinome. Cell Chem Biol. 2018;25:691-704.e6.

60. Bicker KL, Subramanian V, Chumanevich AA, et al. Seeing citrulline: development of a phenylglyoxal-based probe to visualize protein citrullination. $J \mathrm{Am}$ Chem Soc. 2012;134:17015-17018.

61. Lewallen DM, Bicker KL, Subramanian V, et al. Chemical proteomic platform to identify citrullinated proteins. ACS Chem Biol. 2015;10:2520-2528.

62. Sharma M, Damgaard D, Senolt L, et al. Expanding the citrullinome of synovia fibrinogen from rheumatoid arthritis patients. J Proteomics. 2019;208:103484.

63. Correia ML, Carvalho S, Fortuna J, et al. Comparison of three anti-CCP antibody tests and rheumatoid factor in RA and control patients. Clin Rev Allergy Immunol. 2008;34:21-25.

64. Van De Stadt LA, Koning MHMT De, Van De Stadt RJ, et al. Development of the anti-citrullinated protein antibody repertoire prior to the onset of rheumatoid arthritis. Arthritis Rheum. 2011;63:3226-3233.

65. Papamichael K, Tsirogianni A, Papasteriades C, et al. Low prevalence of antibodies to cyclic citrullinated peptide in patients with inflammatory bowel disease regardless of the presence of arthritis. Eur $J$ Gastroenterol Hepatol. 2010;22:705-709.

66. Haga HJ, Palm O, Peen E. Prevalence of IgA class antibodies to cyclic citrullinated peptide in patients with inflammatory bowel disease (IBD). Clin Rheumatol. 2011;30:955-957.

67. Mocelin V, Nisihara RM, Utiyama SR, et al. Anti-CCP antibodies and rheumatological findings in Brazilian patients with Crohn's disease. Digestion 2015;91:303-306

68. Van Erp SJH, Verheul MK, Levarht EWN, et al. Short article: Absence of serological rheumatoid arthritis biomarkers in inflammatory bowel disease patients with arthropathies. Eur J Gastroenterol Hepatol. 2017;29:345-348.

69. Thålin C, Hisada Y, Lundström S, et al. Neutrophil extracellular traps: villains and targets in arterial, venous, and cancer-associated thrombosis. Arterioscler Thromb Vasc Biol. 2019;39:1724-1738.

70. Li Y, Liu B, Fukudome EY, et al. Identification of citrullinated histone $\mathrm{H} 3$ as a potential serum protein biomarker in a lethal model of lipopolysaccharideinduced shock. Surgery. 2011;150:442-451.

71. Pan B, Alam HB, Chong W, et al. CitH3: a reliable blood biomarker for diagnosis and treatment of endotoxic shock. Sci Rep. 2017;7:8972.

72. Paues Göranson S, Thålin C, Lundström A, et al. Circulating H3Cit is elevated in a human model of endotoxemia and can be detected bound to microvesicles. $\mathrm{Sci}$ Rep. 2018;8:12641.

73. Thålin $\mathrm{C}$, Lundström $\mathrm{S}$, Seignez $\mathrm{C}$, et al. Citrullinated histone $\mathrm{H} 3$ as a nove prognostic blood marker in patients with advanced cancer. PLoS One. 2018;13:e0191231 
74. Grilz E, Mauracher LM, Posch F, et al. Citrullinated histone H3, a biomarker for neutrophil extracellular trap formation, predicts the risk of mortality in patients with cancer. Br J Haematol. 2019;186:311-320.

75. Ebrahimi F, Giaglis S, Hahn S, et al. Markers of neutrophil extracellular traps predict adverse outcome in community-acquired pneumonia: secondary analysis of a randomised controlled trial. Eur Respir J. 2018;51:1701389.

76. Mikacenic C, Moore R, Dmyterko V, et al. Neutrophil extracellular traps (NETs) are increased in the alveolar spaces of patients with ventilator-associated pneumonia. Crit Care. 2018;22:358.

77. Noubouossie DF, Reeves BN, Strahl BD, et al. Neutrophils: back in the thrombosis spotlight. Blood. 2019;133:2186-2197.

78. Brill A, Fuchs TA, Savchenko AS, et al. Neutrophil extracellular traps promote deep vein thrombosis in mice. J Thromb Haemost. 2012;10:136-144.

79. Mangold A, Alias S, Scherz T, et al. Coronary neutrophil extracellular trap burden and deoxyribonuclease activity in ST-elevation acute coronary syndrome are predictors of ST-segment resolution and infarct size. Circ Res. 2015;116:1182-1192.

80. Longstaff C, Varjú I, Sótonyi P, et al. Mechanical stability and fibrinolytic resistance of clots containing fibrin, DNA, and histones. $J$ Biol Chem. 2013;288:6946-6956.

81. Savchenko AS, Martinod K, Seidman MA, et al. Neutrophil extracellular traps form predominantly during the organizing stage of human venous thromboembolism development. J Thromb Haemost. 2014;12:860-870.

82. Vallés J, Lago A, Santos MT, et al. Neutrophil extracellular traps are increased in patients with acute ischemic stroke: prognostic significance. Thromb Haemost. 2017;117:1919-1929.

83. Mauracher LM, Posch F, Martinod K, et al. Citrullinated histone H3, a biomarker of neutrophil extracellular trap formation, predicts the risk of venous thromboembolism in cancer patients. $J$ Thromb Haemost. 2018;16:508-518.

84. Yalavarthi S, Gould TJ, Rao AN, et al. Antiphospholipid antibodies promote the release of neutrophil extracellular traps: a new mechanism of thrombosis in the antiphospholipid syndrome. Arthritis Rheumatol. 2015;67:2990-3003.

85. Langseth MS, Opstad TB, Bratseth V, et al. Markers of neutrophil extracellular traps are associated with adverse clinical outcome in stable coronary artery disease. Eur J Prev Cardiol. 2018;25:762-769.

86. Borissoff JI, Joosen IA, Versteylen MO, et al. Elevated levels of circulating DNA and chromatin are independently associated with severe coronary atherosclerosis and a prothrombotic state. Arterioscler Thromb Vasc Biol. 2013;33:2032-2040.

87. Desai RJ, Pawar A, Weinblatt ME, et al. Comparative risk of venous thromboembolism in rheumatoid arthritis patients receiving tofacitinib versus those receiving tumor necrosis factor inhibitors: an observational cohort study. Arthritis Rheumatol. 2019;71:892-900.

88. Sandborn WJ, Panés J, Sands BE, et al. Venous thromboembolic events in the tofacitinib ulcerative colitis clinical development programme. Aliment Pharmacol Ther. 2019;50:1068-1076.

89. Mohanan S, Cherrington BD, Horibata S, et al. Potential role of peptidylarginine deiminase enzymes and protein citrullination in cancer pathogenesis. Biochem Res Int. 2012;2012:895343.

90. Yuzhalin AE, Gordon-Weeks AN, Tognoli ML, et al. Colorectal cancer liver metastatic growth depends on PAD4-driven citrullination of the extracellular matrix. Nat Commun. 2018;9:4783.

91. Slack JL, Causey CP, Thompson PR. Protein arginine deiminase 4: a target for an epigenetic cancer therapy. Cell Mol Life Sci. 2011;68:709-720.

92. Willis VC, Gizinski AM, Banda NK, et al. N- $\alpha$-benzoyl-N5-(2-chloro-1iminoethyl)-L-ornithine amide, a protein arginine deiminase inhibitor, reduces the severity of murine collagen-induced arthritis. J Immunol. 2011;186:4396-4404

93. Knight JS, Zhao W, Luo W, et al. Peptidylarginine deiminase inhibition is immunomodulatory and vasculoprotective in murine lupus. $J$ Clin Invest. 2013;123:2981-2993

94. Knight JS, Subramanian V, O'Dell AA, et al. Peptidylarginine deiminase inhibition disrupts NET formation and protects against kidney, skin and vascular disease in lupus-prone MRL/lpr mice. Ann Rheum Dis. 2015;74:2199-2206.

95. Knight JS, Luo W, O'Dell AA, et al. Peptidylarginine deiminase inhibition reduces vascular damage and modulates innate immune responses in murine models of atherosclerosis. Circ Res. 2014;114:947-956.

96. Causey CP, Jones JE, Slack J, et al. The development of o-F-amidine and o-Clamidine as second generation PAD inhibitors. J Med Chem. 2011;54:6919-6935.

97. Kawalkowska J, Quirke AM, Ghari F, et al Abrogation of collagen-induced arthritis by a peptidyl arginine deiminase inhibitor is associated with modulation of T cell-mediated immune responses. Sci Rep. 2016;6:26430.

98. Jones JE, Slack JL, Fang P, et al. Synthesis and screening of a haloacetamidine containing library to identify PAD4 selective inhibitors. ACS Chem Biol. 2012;7:160-165.

99. Knuckley B, Jones JE, Bachovchin DA, et al. A fluopol-ABPP HTS assay to identify PAD inhibitors. Chem Commun (Camb). 2010;46:7175-7177.

100. Knuckley B, Luo Y, Thompson PR. Profiling protein arginine deiminase 4 (PAD4): a novel screen to identify PAD4 inhibitors. Bioorg Med Chem. 2008;16:739-745.

101. Pritzker LB, Moscarello MA. A novel microtubule independent effect of paclitaxel: the inhibition of peptidylarginine deiminase from bovine brain. Biochim Biophys Acta. 1998;1388:154-160.
102. Mondal S, Gong X, Zhang X, et al. Halogen bonding increases the potency and isozyme selectivity of protein arginine deiminase 1 inhibitors. Angew Chem Int Ed Engl. 2019;58:12476-12480.

103. Tejeda EJC, Bello AM, Wasilewski E, et al. Noncovalent protein arginine deiminase (PAD) inhibitors are efficacious in animal models of multiple sclerosis. I Med Chem. 2017;60:8876-8887.

104. Koushik S, Joshi N, Nagaraju S, et al. PAD4: pathophysiology, current therapeutics and future perspective in rheumatoid arthritis. Expert Opin Ther Targets 2017;21:433-447.

105. Aliko A, Kamińska M, Falkowski K, et al. Discovery of novel potential reversible peptidyl arginine deiminase inhibitor. Int J Mol Sci. 2019;20:E2174.

106. Lewis HD, Liddle J, Coote JE, et al. Inhibition of PAD4 activity is sufficient to disrupt mouse and human NET formation. Nat Chem Biol. 2015;11:189-191.

107. Kosgodage US, Matewele P, Mastroianni G, et al. Peptidylarginine deiminase inhibitors reduce bacterial membrane vesicle release and sensitize bacteria to antibiotic treatment. Front Cell Infect Microbiol. 2019;9:227.

108. Willis VC, Banda NK, Cordova KN, et al. Protein arginine deiminase 4 inhibition is sufficient for the amelioration of collagen-induced arthritis. Clin Exp Immunol. 2017; 188:263-274.

109. Cedervall J, Dragomir A, Saupe F, et al. Pharmacological targeting of peptidylarginine deiminase 4 prevents cancer-associated kidney injury in mice Oncoimmunology. 2017;6:e1320009.

110. Wei L, Wasilewski E, Chakka SK, et al. Novel inhibitors of protein arginine deiminase with potential activity in multiple sclerosis animal model. $J$ Med Chem 2013;56:1715-1722.

111. Chang S, Malter L, Hudesman D. Disease monitoring in inflammatory bowel disease. World J Gastroenterol. 2015;21:11246-11259.

112. Senshu T, Kan S, Ogawa H, et al. Preferential deimination of keratin K1 and filaggrin during the terminal differentiation of human epidermis. Biochem Biophys Res Commun. 1996;225:712-719.

113.Ishida-Yamamoto A, Senshu T, Takahashi H, et al. Decreased deiminated keratin $\mathrm{K} 1$ in psoriatic hyperproliferative epidermis. $J$ Invest Dermatol. 2000;114:701-705.

114. Ishida-Yamamoto A, Senshu T, Eady RA, et al. Sequential reorganization of cornified cell keratin filaments involving filaggrin-mediated compaction and keratin 1 deimination. $J$ Invest Dermatol. 2002;118:282-287.

115. Qin H, Liu X, Li F, et al. PAD1 promotes epithelial-mesenchymal transition and metastasis in triple-negative breast cancer cells by regulating MEK1-ERK1/2 MMP2 signaling. Cancer Lett. 2017;409:30-41.

116. Horibata S, Coonrod SA, Cherrington BD. Role for peptidylarginine deiminase enzymes in disease and female reproduction. J Reprod Dev. 2012;58:274-282.

117. Cantariño N, Musulén E, Valero V, et al. Downregulation of the deiminase PADI2 is an early event in colorectal carcinogenesis and indicates poor prognosis. Mol Cancer Res. 2016;14:841-848.

118. Sharma P, Lioutas A, Fernandez-Fuentes N, et al. Arginine citrullination at the C-terminal domain controls RNA polymerase II transcription. Mol Cell. 2019;73:84-96.e7.

119. Wang L, Song G, Zhang X, et al. PADI2-mediated citrullination promotes prostate cancer progression. Cancer Res. 2017;77:5755-5768.

120. Chavanas S, Adoue V, Méchin MC, et al. Long-range enhancer associated with chromatin looping allows AP-1 regulation of the peptidylarginine deiminase 3 gene in differentiated keratinocyte. PLoS One. 2008;3:e3408.

121. $\ddot{U}$ Basmanav FB, Cau L, Tafazzoli A, et al. Mutations in three genes encoding proteins involved in hair shaft formation cause uncombable hair syndrome. $A m$ Hum Genet. 2016;99:1292-1304.

122. Wang Y, Wysocka J, Sayegh J, et al. Human PAD4 regulates histone arginine methylation levels via demethylimination. Science. 2004;306:279-283.

123. Yao H, Li P, Venters BJ, et al. Histone Arg modifications and p53 regulate the expression of OKL38, a mediator of apoptosis. J Biol Chem. 2008;283:20060-20068

124. Liu M, Qu Y, Teng X, et al. PADI4-mediated epithelial-mesenchymal transition in lung cancer cells. Mol Med Rep. 2019;19:3087-3094.

125. Chang X, Han J, Pang L, et al. Increased PADI4 expression in blood and tissues of patients with malignant tumors. BMC Cancer. 2009;9:40.

126. Chang X, Hou X, Pan J, et al. Investigating the pathogenic role of PADI4 in oesophageal cancer. Int J Biol Sci. 2011;7:769-781.

127. Wang L, Chang X, Yuan G, et al. Expression of peptidylarginine deiminase type 4 in ovarian tumors. Int J Biol Sci. 2010;6:454-464.

128. Xin J, Song X. Role of peptidylarginine deiminase type 4 in gastric cancer. Exp Ther Med. 2016;12:3155-3160.

129. Mastronardi FG, Wood DD, Mei J, et al. Increased citrullination of histone $\mathrm{H} 3$ in multiple sclerosis brain and animal models of demyelination: a role for tumor necrosis factor-induced peptidylarginine deiminase 4 translocation. $J$ Neurosci. 2006;26:11387-11396.

130. Sorvillo N, Mizurini DM, Coxon C, et al. Plasma peptidylarginine deiminase IV promotes VWF-platelet string formation and accelerates thrombosis after vessel injury. Circ Res. 2019;125:507-519.

131. Esposito G, Vitale AM, Leijten FP, et al. Peptidylarginine deiminase (PAD) 6 is essential for oocyte cytoskeletal sheet formation and female fertility. $\mathrm{Mol}$ Cell Endocrinol. 2007;273:25-31. 
132. Wright PW, Bolling LC, Calvert ME, et al. ePAD, an oocyte and early embryoabundant peptidylarginine deiminase-like protein that localizes to egg cytoplasmic sheets. Dev Biol. 2003;256:73-88.

133. Xu Y, Shi Y, Fu J, et al. Mutations in PADI6 cause female infertility characterized by early embryonic arrest. Am J Hum Genet. 2016;99:744-752.

134. Qian J, Nguyen NMP, Rezaei M, et al. Biallelic PADI6 variants linking infertility, miscarriages, and hydatidiform moles. Eur J Hum Genet. 2018;26:1007-1013.

135. Lange S, Gögel S, Leung KY, et al. Protein deiminases: new players in the developmentally regulated loss of neural regenerative ability. Dev Biol. 2011;355:205-214.

136. Li P, Yao H, Zhang Z, et al. Regulation of p53 target gene expression by peptidylarginine deiminase 4. Mol Cell Biol. 2008;28:4745-4758.

137. Wang Y, Li M, Stadler S, et al. Histone hypercitrullination mediates chromatin decondensation and neutrophil extracellular trap formation. $J$ Cell Biol. 2009:184:205-213.

138. Smith CK, Vivekanandan-Giri A, Tang C, et al. Neutrophil extracellular trap-derived enzymes oxidize high-density lipoprotein: an additional proatherogenic mechanism in systemic lupus erythematosus. Arthritis Rheumatol. 2014;66:2532-2544.

139. Lange S, Rocha-Ferreira E, Thei L, et al. Peptidylarginine deiminases: novel drug targets for prevention of neuronal damage following hypoxic ischemic insult (HI) in neonates. $J$ Neurochem. 2014;130:555-562.
140. Luo Y, Knuckley B, Lee YH, et al. A fluoroacetamidine-based inactivator of protein arginine deiminase 4: design, synthesis, and in vitro and in vivo evaluation. Am Chem Soc. 2006;128:1092-1093.

141. Knuckley B, Causey CP, Jones JE, et al. Substrate specificity and kinetic studies of PADs 1,3 , and 4 identify potent and selective inhibitors of protein arginine deiminase 3. Biochemistry. 2010;49:4852-4863.

142. Bicker KL, Anguish L, Chumanevich AA, et al. D-amino acid-based protein arginine deiminase inhibitors: Synthesis, pharmacokinetics, and in cellulo efficacy. ACS Med Chem Lett. 2012;3:1081-1085.

143. Moscarello MA, Lei H, Mastronardi FG, et al. Inhibition of peptidyl-arginine deiminases reverses protein-hypercitrullination and disease in mouse models of multiple sclerosis. DMM Dis Model Mech. 2013;6:467-478.

144. Subramanian V, Knight JS, Parelkar S, et al. Design, synthesis, and biological evaluation of tetrazole analogs of $\mathrm{Cl}$-amidine as protein arginine deiminase inhibitors. J Med Chem. 2015;58:1337-1344.

145. Wang Y, Li P, Wang S, et al. Anticancer peptidylarginine deiminase (PAD) inhibitors regulate the autophagy flux and the mammalian target of rapamycin complex 1 activity. J Biol Chem. 2012;287:25941-25953.

146. Jamali H, Khan HA, Tjin CC, et al. Cellular activity of new small molecule protein arginine deiminase 3 (PAD3) inhibitors. ACS Med Chem Lett. 2016;7: $847-851$ 